Faculty of Science

Faculty Publications

This is a post-review version of the following article:

Oxidation of Methylalumoxane Oligomers

Harmen S. Zijlstra, Scott Collins and J. Scott McIndoe

April 2018

The final published version of this article can be found at:

https://doi.org/10.1002/chem.201705458

Citation for this paper:

Zijlstra, H.S., Collins, S. \& McIndoe, J.S. (2018). Oxidation of Methylalumoxane Oligomers. Chemistry: A European Journal, 24(21), 5506-5512. 


\title{
Oxidation of Methylalumoxane Oligomers
}

\author{
Harmen S. Zijlstra, ${ }^{[a]}$ Scott Collins ${ }^{[a]}$ and J. Scott McIndoe ${ }^{[a] *}$ \\ [a] Department of Chemistry, University of Victoria, P. O. Box 3065 Victoria BC V8W3V6, Canada.
}

Keywords: Methylalumoxane, Activators, Cocatalysts, Mass Spectrometry, Homogeneous Catalysis

\begin{abstract}
The anions formed from methylalumoxane (MAO) and suitable donors (e.g. octamethyltrisiloxane) are amenable to mass spectrometric (MS) analysis. Their composition as deduced from this data allows direct insight into the chemical transformations of their neutral precursors. One such process is oxidation, which is well-known to be facile for MAO without any clear idea of what actually occurs at a molecular level. Addition of $\mathrm{O}_{2}$ to MAO results in immediate gelation, but MS analysis reveals no corresponding change to the composition of the principal oligomeric anions. A slow (hours) reaction does occur that involves net incorporation of $\mathrm{Me}_{2} \mathrm{AlOMe}$ into the oligomeric anions, and the identities of the OMe-containing anions were confirmed by ${ }^{1} \mathrm{H}$ NMR spectroscopy, MS/MS analysis, and addition of an authentic sample of $\mathrm{Me}_{2} \mathrm{AIOMe}$ to MAO. The result tallies with the fact that addition of $\mathrm{O}_{2}$ to MAO produces $\mathrm{Me}_{2} \mathrm{AlOMe}$ from free $\mathrm{Me}_{3} \mathrm{Al}$ which eventually leads to formation of oxidized MAO oligomers and changes in ion abundance. Aging of the oxygenated MAO results in further growth of the oligomers similar to that of the non-oxidized species. Mass spectrometric analysis therefore reveals useful insights into the environmental history of a given MAO batch.
\end{abstract}

\section{Introduction}

Methylalumoxane (MAO) is widely used as an activator of olefin polymerization catalysts. ${ }^{[1]}$ $\mathrm{MAO}$ is produced by the controlled, partial hydrolysis of trimethylaluminum $\left(\mathrm{Me}_{3} \mathrm{Al}\right)$ giving a mixture of oligomers and residual $\mathrm{Me}_{3} \mathrm{Al}$ that are in dynamic equilibrium. ${ }^{\left[{ }^{2]}\right.}$ This complex mixture varies in composition over time, making it very hard to characterize. Its average composition, $\left(\mathrm{Me}_{1.4-1.5} \mathrm{AlO}_{0.75-0.80}\right)_{n},{ }^{[3]}$ molecular weight $(\mathrm{MW}, \sim 1200-2000)$ and degree of polymerization $(n=$ $20-30)^{[4]}$ are largely agreed upon. The consensus of all this work and computational studies ${ }^{[5]}$ is that MAO is made up of cage-like structures that have the general formula $(\mathrm{MeAlO})_{\mathrm{n}}\left(\mathrm{Me}_{3} \mathrm{Al}\right)_{\mathrm{m}}$ where a large number of structures are expected to be stable. 
MAO is used as an activator in polymerization catalysis because it both alkylates and ionizes the catalyst precursor, but it also plays an important role as a scavenger of impurities in solvent and monomer, especially in slurry processes. ${ }^{[6]}$ Water, oxygen and carbon dioxide are ubiquitous impurities in gaseous monomers or liquid diluents, and are typically reduced to ppm levels by passage through various purification towers on a commercial scale. These impurities are reactive towards transition metal carbon bonds and will deactivate catalysts if present. The alkylaluminum scavenger brings these impurities down to the sub-ppm levels necessary for use with metallocene and other highly active single-site catalysts.

Oxidation of aluminum alkyls by molecular oxygen to furnish aluminum alkoxides, and ultimately alcohols, is the basis for the commercial synthesis of long, chain primary alcohols that is still practiced on large scale. ${ }^{[7]}$ This reaction can also be used to prepare polyolefinic alcohols through oxidation of polymeric organoaluminum compounds generated by chain transfer to Al. ${ }^{[8]}$ Despite the importance of this process, very little is known about the oxidation chemistry of MAO itself, though as it contains free trimethylaluminum, it is reasonable to expect the material to undergo facile oxidation by $\mathrm{O}_{2}$. The reaction of $\mathrm{Me}_{3} \mathrm{Al}$ with a deficit of oxygen generates $\mathrm{Me}_{2} \mathrm{AlOMe}$, though the mechanism of the reaction is unclear. ${ }^{\left[{ }^{[9]}\right.}$ While the reaction of $\mathrm{Me}_{3} \mathrm{Ga}$ with $\mathrm{O}_{2}$ was shown to form the $\mathrm{Me}_{2} \mathrm{GaOOMe}$ insertion product, ${ }^{[10]}$ the reaction of $\mathrm{O}_{2}$ with $\mathrm{Me}_{3} \mathrm{Al}$ does not form a stable peroxide. Instead it was proposed that $\mathrm{O}_{2}$ reacts directly with the $\mathrm{Me}_{6} \mathrm{Al}_{2}$ dimer to form two equivalents of $\mathrm{Me}_{2} \mathrm{AlOMe} .^{[11]}$

In recent years, electrospray ionization mass spectrometry (ESI-MS) has been used to study metallocinium ions in olefin polymerization. ${ }^{[12,13]}$ We have shown that under anaerobic conditions ESI-MS is also an unusually insightful tool with which to study the speciation and chemical behavior of MAO. ${ }^{[14]}$ Upon reaction of MAO with $\mathrm{Cp}_{2} \mathrm{ZrX}_{2}(\mathrm{X}=\mathrm{Cl}$ or $\mathrm{Me})$, octamethyltrisiloxane (OMTS), or $\left[n \mathrm{Bu}_{4} \mathrm{~N}\right]^{+} \mathrm{Cl}^{-}$, a series of ion pairs of the general formula $[\mathrm{M}]^{+}\left[(\mathrm{MeAlO})_{\mathrm{x}}\left(\mathrm{Me}_{3} \mathrm{Al}\right)_{\mathrm{y}} \mathrm{Me}\right]^{-}$ are formed $\left([\mathrm{M}]^{+}=\left[\mathrm{Cp}_{2} \mathrm{Zr}(\mu-\mathrm{Me})_{2} \mathrm{AlMe}_{2}\right]^{+},\left[\mathrm{Me}_{2} \mathrm{Al}-\mathrm{OMTS}\right]^{+},\left[n \mathrm{Bu}_{4} \mathrm{~N}\right]^{+}\right)$. In the case of OMTS, the anion distribution changes with OMTS:Al ratio, with low MW anions forming at high ratios while higher MW anions form over time through sequential addition of (MeAIO) and $\mathrm{Me}_{3} \mathrm{Al}$ units to the original anions observed. ${ }^{[14 b]}$

Here, we extend our mass spectrometric investigations of MAO to its reaction with oxygen with the intent of (a) examining this fundamental reaction to establish exactly what happens at a molecular level and (b) to better account for some of the different anions observed in aged samples of MAO studied previously. ${ }^{[14 d]}$ 


\section{Results and Discussion}

We previously noted the difference in ions between $10 \mathrm{wt} \%$ MAO samples obtained from Sigma-Aldrich, which stopped selling MAO in 2014, and Albemarle (see Supplemental Information figure S2). ${ }^{[14 b]}$ The Albemarle material contained low MW anions while the distribution in the Sigma-Aldrich material was shifted towards higher MW indicating an older sample age. While these differences did not seem to affect the polymerization behavior of $\mathrm{Cp}_{2} \mathrm{ZrX}_{2}(\mathrm{X}=\mathrm{Cl}, \mathrm{Me})$ when using different MAO samples, ${ }^{[14 a]}$ we do note that the aged MAO samples obtained from Sigma Aldrich had generally lower contents of $\left[\mathrm{Me}_{2} \mathrm{Al}\right]^{+}$, as determined by NMR spectroscopy. ${ }^{[14 a, 14 c]}$ As a result, one needed more of the aged MAO (ca. $2 \times$ larger amounts) to achieve the same level of activation compared to fresh samples provided by Albemarle. Additionally, the Sigma-Aldrich material also contained a series of anions not observed in the Albemarle material. This series of anions has a mass $42 \mathrm{Da}$ below the main $\left[(\mathrm{MeAlO})_{x}\left(\mathrm{Me}_{3} \mathrm{Al}\right)_{\mathrm{y}} \mathrm{Me}\right]^{-}$series observed in both samples.

However, when investigating a refrigerated sample of 10 wt\% MAO from Albemarle that was over three years old, we saw the appearance of a new signal 42 Da below the most abundant $x$ $=16, y=6$ anion (henceforth 16,6, Figure 1a and inset). Close inspection of the spectrum revealed $-42 \mathrm{Da}$ ions for the 17,6 and 18,6 anions as well. After storage at room temperature for 4 days the expected increase in molecular weight occurred through addition of (MeAIO) units to both series of ions (Figure 1b). 


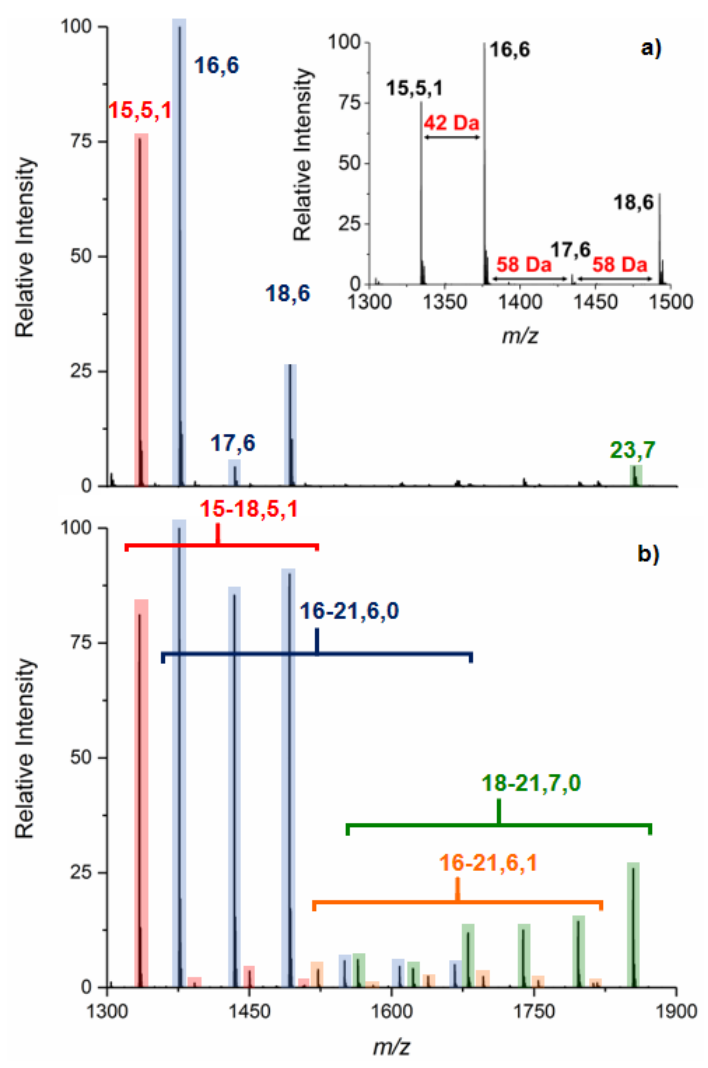

Figure 1. Negative ion ESI-MS spectra in PhF of an old, partially oxidized sample of $10 \mathrm{wt} \%$ Albemarle MAO with an OMTS:Al ratio of 1:100; (a) right after preparation and (b) 4 days later.

The most straightforward way to explain the 42 Da mass difference is to formally add an $\mathrm{O}$ atom into a MAO anion containing one less MeAIO unit (16 - 58 $=-42)$. These partially oxidized MAO anions might then have the general formula $\left[(\mathrm{MeAlO})_{x}\left(\mathrm{Me}_{3} \mathrm{Al}\right)_{y}\left(\mathrm{Me}_{2} \mathrm{AlOMe}\right)_{z} \mathrm{Me}\right]^{-}$. Thus, the anion 42 Da below 16,6 would correspond to 15,5,1. To test this we compared the MS/MS spectra of both 16,6 and $15,5,1$ (Figure 2).

Their MS/MS spectra show one main difference, namely where the 16,6 loses only $\mathrm{Me}_{3} \mathrm{Al}$ fragments $(72 \mathrm{Da}),{ }^{[15]}$ the $\mathbf{1 5 , 5 , 1}$ oligomer loses $\mathrm{Me}_{2} \mathrm{AlOMe}(88 \mathrm{Da})$ fragments but only at higher collision energy. We previously attributed this observation to loss of $\mathrm{CH}_{4}$ (a well-documented process for $\mathrm{MAO}^{[14 d, 16]}$ ) but a combination of in-source $\mathrm{CID}$ and MS/MS experiments on $\mathbf{1 5 , 5 , 1}$ vs. its fragment ions confirm that the loss is actually $\mathrm{Me}_{2} \mathrm{AlOMe}$ (88 $\mathrm{Da}$, see Supporting Information Figure S5). The MS/MS spectra of all higher MW $x, y, z$ oligomers that could be obtained are analogous with the previously reported $x, y$ species, the only difference being that the $\mathrm{Me}_{3} \mathrm{Al}$ losses are accompanied by $\mathrm{Me}_{2} \mathrm{AlOMe}$ losses, with their number depending on $\mathrm{z}$. In view of these MS/MS spectra these oxidized anions are best formulated as $\left[(\mathrm{MeAlO})_{x}\left(\mathrm{Me}_{3} \mathrm{Al}\right)_{y}\left(\mathrm{Me}_{2} \mathrm{AlOMe}\right)_{z} \mathrm{Me}\right]^{-}$. 

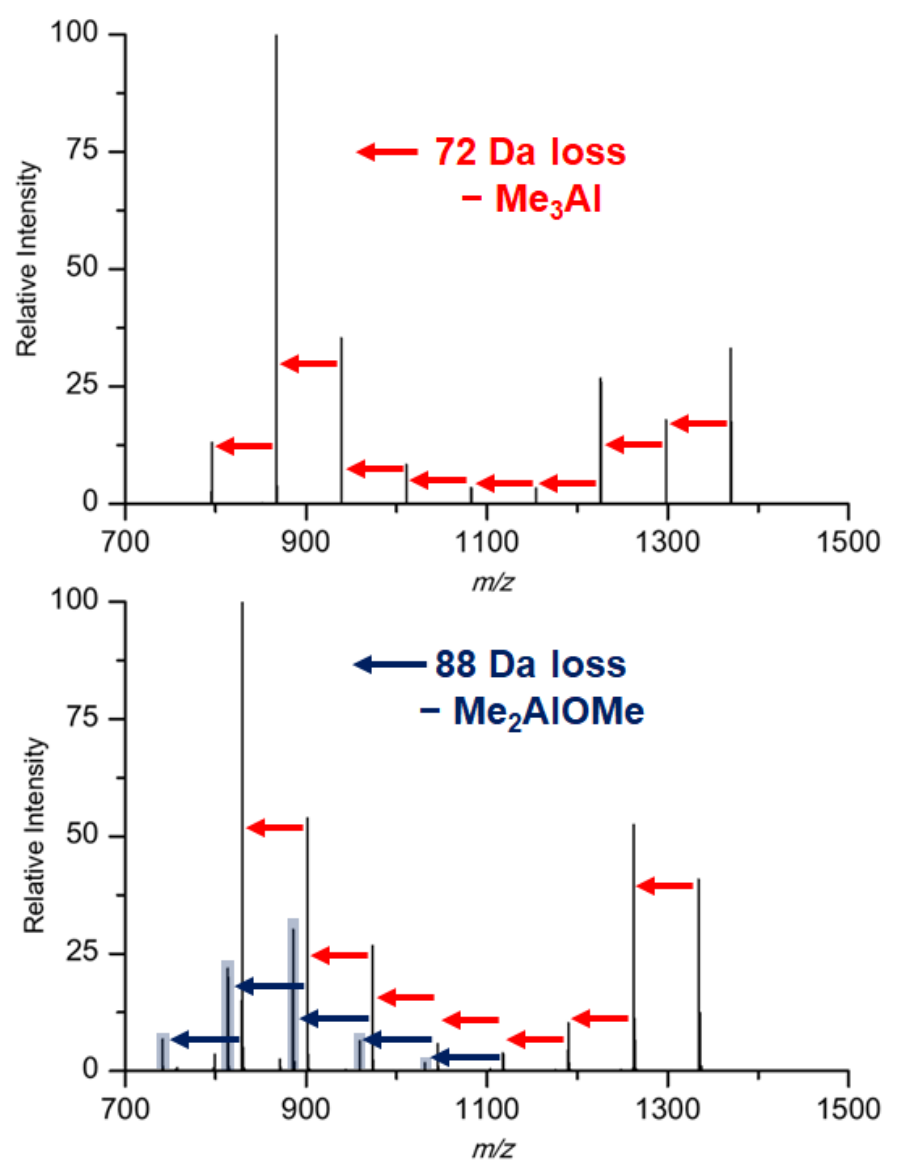

Figure 2. $\mathrm{MS} / \mathrm{MS}$ of $\left[(\mathrm{MeAlO})_{16}\left(\mathrm{Me}_{3} \mathrm{Al}\right)_{6} \mathrm{Me}\right]^{-}$(top) and $\left[(\mathrm{MeAlO})_{15}\left(\mathrm{Me}_{3} \mathrm{Al}\right)_{5}\left(\mathrm{Me}_{2} \mathrm{AlOMe}\right) \mathrm{Me}\right]^{-}$(bottom).

Formation of Al-O-Me groups is further confirmed by analysis of the ${ }^{1} \mathrm{H}$ NMR spectrum of the 10 $w t \%$ Albemarle MAO. The spectrum shows O-Me peaks (e.g. Figure 3$),{ }^{[3]}$ which when integrated to the $\mathrm{Al}-\mathrm{Me}$ groups, are present in a 1:103 \pm 2 ratio after correction for the $\mathrm{Me}_{3} \mathrm{Al}$ content of this sample (see Supplementary Information). This observation means that approximately $1 \mathrm{~mol} \%$ of all Me groups in this sample of MAO are oxidized.

The ESI-MS (Figure 1a) normalized intensity data for the ions with $\mathrm{m} / \mathrm{z} 1333(\mathbf{1 5 , 5 , 1 )}, 1375$ $(16,6), 1433(17,6)$ and $1491(18,6$; ca. $80-85 \%$ of the total ion intensity) was analyzed to provide mole fractions of $0.31,0.49,0.028$, and 0.17 , respectively for these ions. The $15,5,1$ ion contains one O-Me and 32 Al-Me groups, while the others contain 35-37 Al-Me groups, respectively. One can thus calculate that there is one AlOMe group for every $108 \pm 2 \mathrm{Al}-\mathrm{Me}$ groups, in good agreement with the amount of oxidation estimated by NMR spectroscopy. 


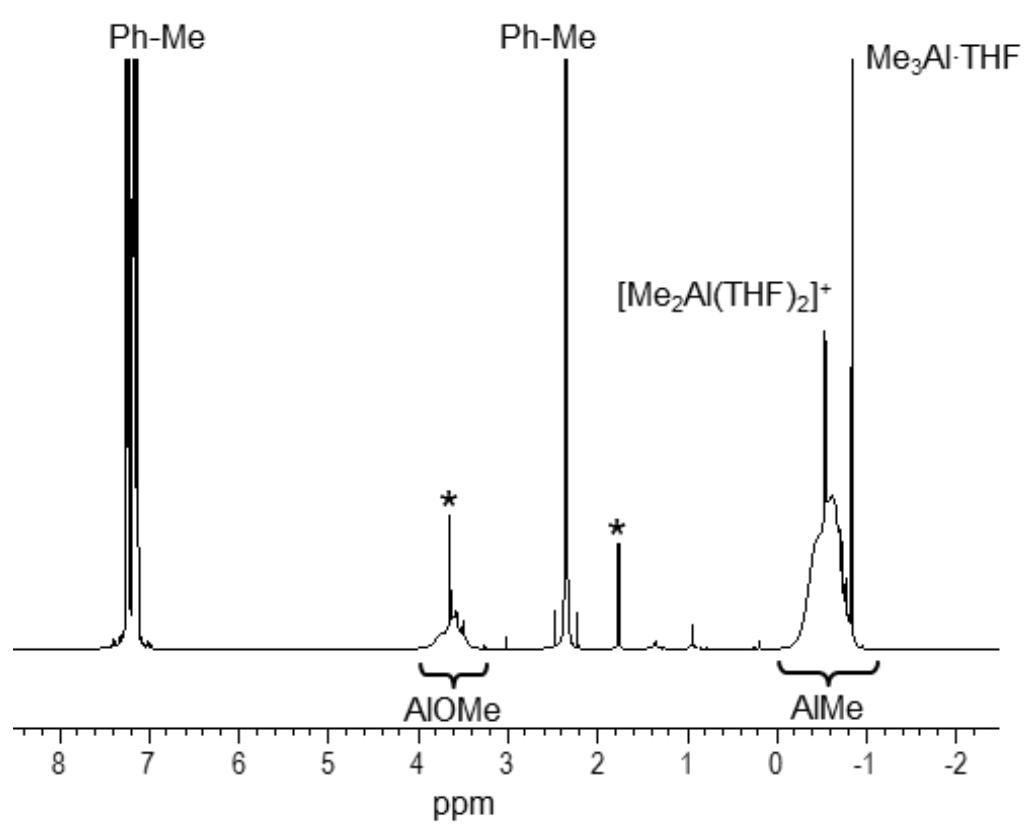

Figure 3. ${ }^{1} \mathrm{H}$ NMR spectrum of oxidized MAO (30 wt\% in toluene) in THF- $\mathrm{d}_{8}$ with assignments. Residual THF- $\mathrm{d}_{7}$ signals indicated with *.

To study the oxidation process in more detail we investigated the oxidation of a refrigerated, 6month-old sample of $30 \mathrm{wt} \% \mathrm{MAO}$ obtained from Albemarle. The negative ion spectrum of this material was found to be identical to that of an unaged, and unoxidized sample of $10 \mathrm{wt} \%$ MAO while the $30 \mathrm{wt} \%$ material was found to contain $12.1 \mathrm{~mol} \% \mathrm{Me}_{3} \mathrm{Al}$ and $1.55 \mathrm{~mol} \%$ $\left[\mathrm{Me}_{2} \mathrm{Al}(\mathrm{THF})_{2}\right]^{+}$by NMR spectroscopy. ${ }^{[17]}$ It should be noted that the spectrum of $30 \mathrm{wt} \% \mathrm{MAO}$ with OMTS (OMTS:Al 1:100) showed signs of minor oxidation and some aging (e.g. Figure 6a, vide infra). Due to its increased concentration ([Al] $=4.6 \mathrm{M}$ for $30 \mathrm{wt} \% \mathrm{MAO}$ vs. $1.5 \mathrm{M}$ for $10 \mathrm{wt} \%$ MAO) this material is much harder to maintain in good condition and minor changes in ion composition were observed during the course of these studies (6 months).

Immediately upon exposure of a dilute solution of this material in toluene to oxygen a gel layer formed. The solution was filtered and its negative ion ESI-MS spectra measured. Surprisingly, in light of the gelatinous layer, no oxidation of the anions was observed and only 16,6 was present. When, however, the same sample was measured again the next day a completely different spectrum was obtained (Figure 4). 


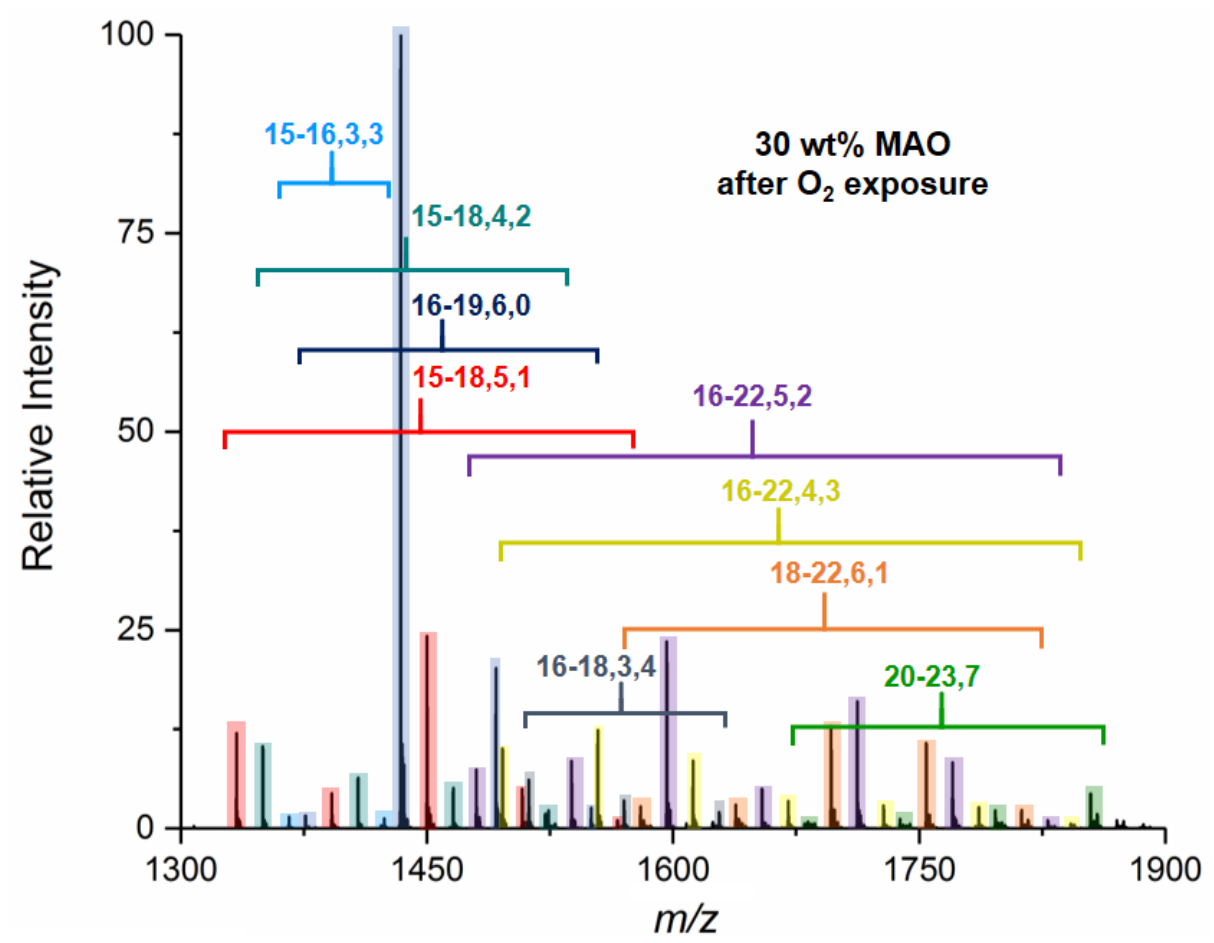

Figure 4. Negative ion ESI-MS spectra in PhF of 30 wt \% Albemarle MAO with an OMTS:Al ratio of 1:100, one day after $\mathrm{O}_{2}$ exposure.

A wide variety of new anions had appeared assignable to the general formula $\left[(\mathrm{MeAlO})_{x}\left(\mathrm{Me}_{3} \mathrm{Al}\right)_{y}\left(\mathrm{Me}_{2} \mathrm{AlOMe}\right)_{z} \mathrm{Me}\right]^{-}$(where $\left.z=0-4\right)$. The mass spectrum is reminiscent in terms of complexity to that seen when $\mathrm{MAO}$ is used to activate $\mathrm{Cp}_{2} \mathrm{ZrCl}_{2}{ }^{[14 c]}$ or the ion-pairs formed from MAO and $\mathrm{Cp}_{2} \mathrm{ZrMe}_{2}$ are treated with $\mathrm{Me}_{2} \mathrm{AICl}$ and ions differing $20 \mathrm{Da}(\mathrm{Me} / \mathrm{Cl})$ in mass are observed. ${ }^{[14 a]}$ In that case, ions with the same basic formula $\left[(\mathrm{MeAlO})_{\mathrm{x}}\left(\mathrm{Me}_{3} \mathrm{Al}\right)_{\mathrm{y}}\left(\mathrm{Me}_{2} \mathrm{AlCl}\right)_{z} \mathrm{Me}\right]^{-}$are formed by displacement of bound $\mathrm{Me}_{3} \mathrm{Al}$ by $\mathrm{Me}_{2} \mathrm{AlCl}$.

We thus expected a similar process is occurring during oxidation of $\mathrm{MAO}$; in this case however, it is the neutral components undergoing exchange of $\mathrm{Me}_{2} \mathrm{AlOMe}$ which are subsequently ionized. As oxidation of $\mathrm{Me}_{3} \mathrm{Al}$ and other aluminum alkyls is rapid, ${ }^{[6-9]}$ the slow changes observed to the anion distribution reflects slow exchange of bound $\mathrm{Me}_{3} \mathrm{Al}$ by $\mathrm{Me}_{2} \mathrm{AlOMe}$.

As uncontrolled oxidation of MAO solutions leads to gel formation and necessitates physical fractionation of the sample, we opted for a different approach. For this we monitored the changes in MAO speciation in an oxygen-saturated toluene solution $\left[\mathrm{O}_{2}\right] \sim 4.5 \mathrm{mM}$ at $298 \mathrm{~K}$ and 1 atm. Initially, no differences were detected but over the course of two weeks dramatic transformations had occurred, and the $\mathrm{x}, \mathrm{y}$ series had not just increased in molecular weight but also evolved into an $x, y, z$ series (where $z=1$, Figure 5 ) due to the oxygen present. 


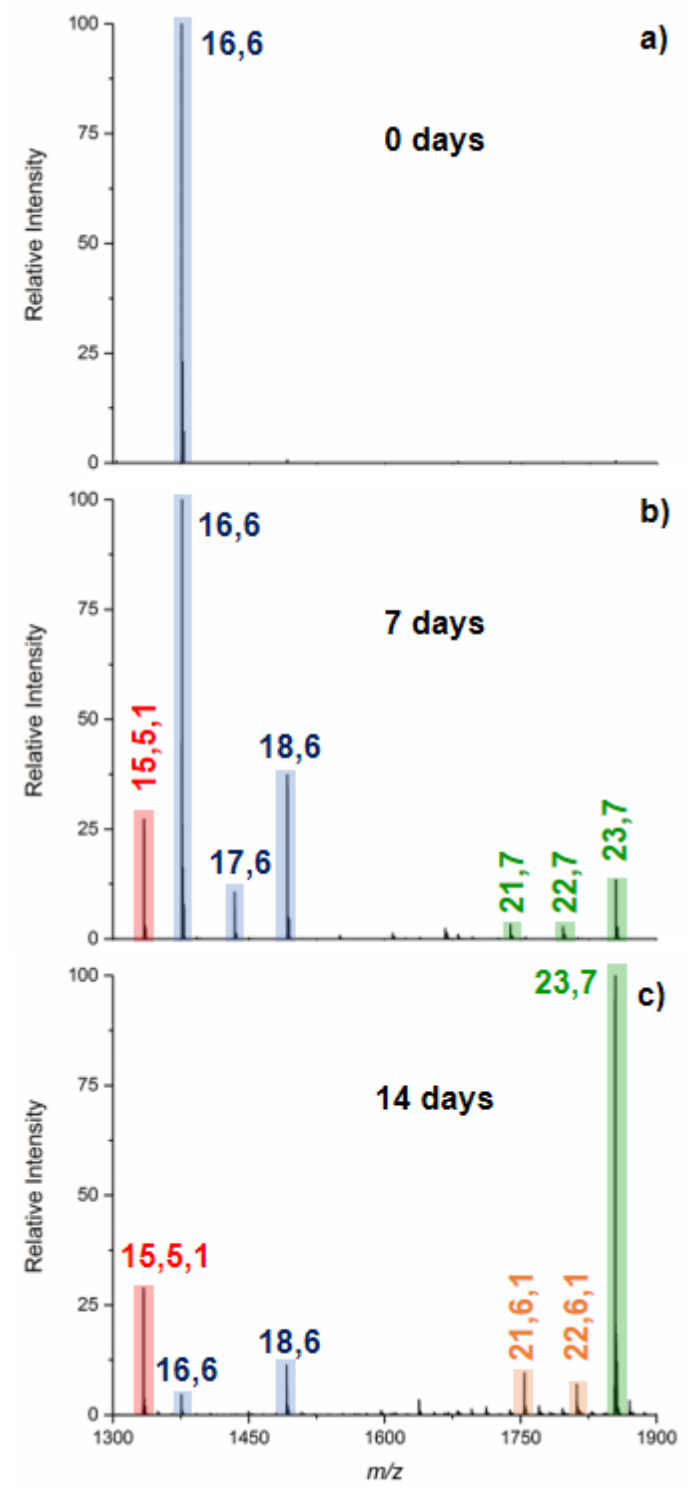

Figure 5. Negative ion spectra of MAO sample dissolved in $\mathrm{O}_{2}$ saturated toluene at (a) 0 days, (b) 7 days and (c) 14 days.

Control experiments with regular MAO and MAO diluted with non-oxygenated toluene further indicate this is due to oxidation as the amount of 15,5,1 observed is almost non-existent in regular MAO and is much lower in sample diluted with non-oxygenated toluene (see supplemental Information figure S4). Lowering the amount of oxygen present limits the amount of different oxidized MAO anions that form but the slow exchange reaction leads to competitive oxidation and aging.

Injection of $\mathrm{Me}_{2} \mathrm{AlOMe}$ solution into a MAO solution might therefore provide more direct insight into the incorporation of these groups into MAO oligomers (Figure 6). Comparison of the $30 \mathrm{wt} \%$ 
sample with the sample containing $10 \mathrm{~mol} \% \mathrm{Me}_{2} \mathrm{AIOMe}$ show detectable differences (Figure 6a and b).
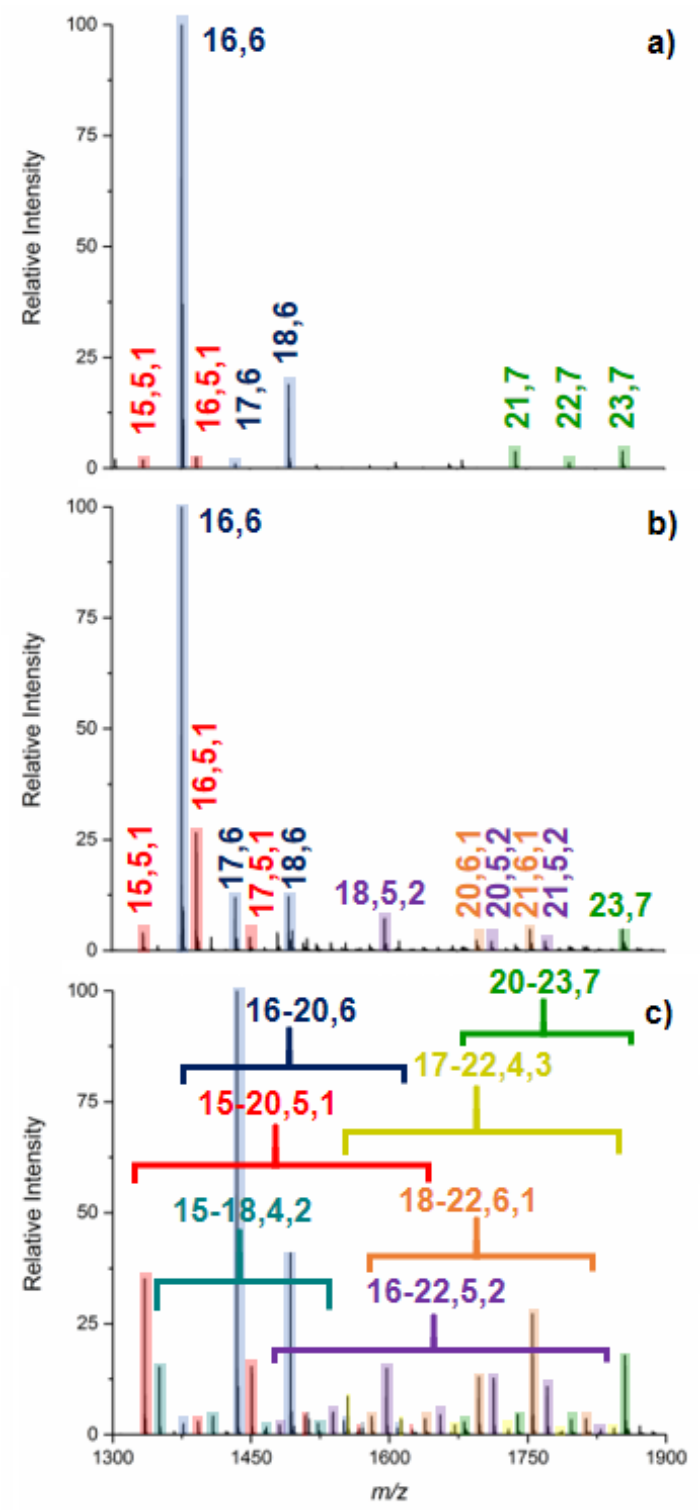

Figure 6. Negative ion spectra of (a) regular $30 \mathrm{wt} \% \mathrm{MAO}$, (b) $30 \mathrm{wt} \% \mathrm{MAO}+10 \mathrm{~mol} \% \mathrm{Me}_{2} \mathrm{AlOMe}$ directly after preparation, and (c)30 wt $\% \mathrm{MAO}+10 \mathrm{~mol} \% \mathrm{Me}_{2} \mathrm{AlOMe}$ one day later.

Upon addition of $\mathrm{Me}_{2} \mathrm{AlOMe}$, all anions feature $\mathrm{M}+16$ and $\mathrm{M}+32 \mathrm{Da}$ signals consistent with displacement of $\mathrm{Me}_{3} \mathrm{Al}$ by $\mathrm{Me}_{2} \mathrm{AlOMe}$. If, however, the same $\mathrm{Me}_{2} \mathrm{AlOMe}$-containing sample is measured again the next day a more complex spectrum is obtained (Figure 1c). Now various series of oxidized MAO oligomers are present, and an ion distribution very similar to the sample 
directly exposed to oxygen is obtained (Figure 4). It is interesting to note that $\mathbf{1 6 , 6}$ and $\mathbf{1 6 , 5 , 1}$ are the most dominant ions in the spectra obtained directly after addition of $\mathrm{Me}_{2} \mathrm{AlOMe}$ to MAO. One day later both these species are only found in minor amounts and now 17,6 and 15,5,1 are the dominant ions present. This suggests that oxidation of MAO leads to a structural rearrangement which results in an oxidized oligomer that is one MeAIO unit lower in MW and an unoxidized cluster which contains more MeAIO units. A possible explanation of the reactivity appears in Scheme 1.

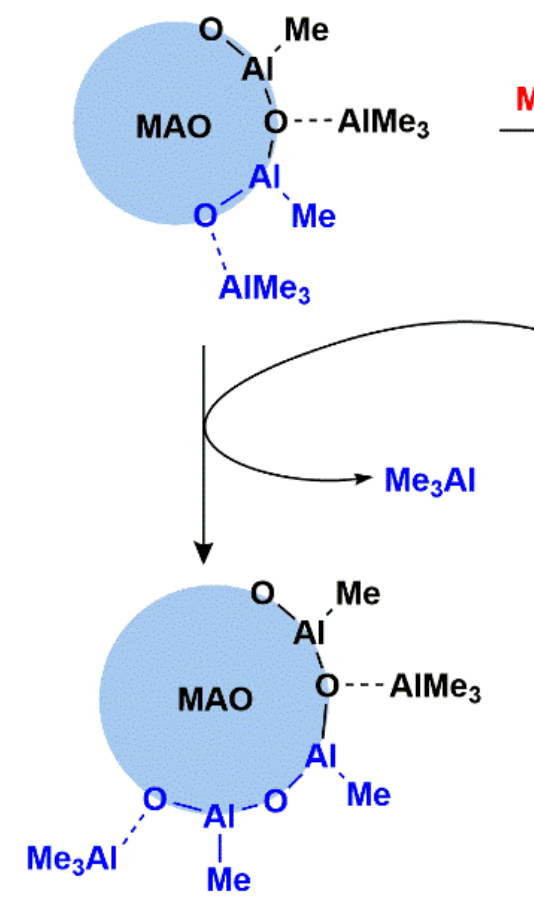

Increased MW oligomers
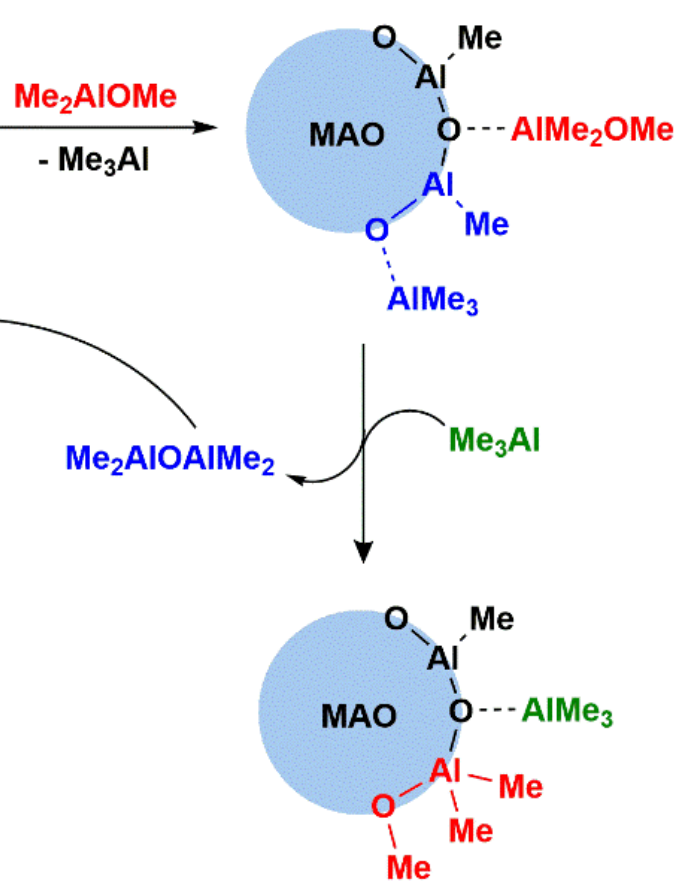

Oxidized oligomers

Scheme 1. Proposed reaction of $\mathrm{MAO}$ with $\mathrm{Me}_{2} \mathrm{AlOMe}$ and subsequent rearrangement to give both oxidized and increased MW oligomers

The neutral precursor of 16,6 initially undergoes $\mathrm{Me}_{3} \mathrm{Al} / \mathrm{Me}_{2} \mathrm{AlOMe}$ exchange to give the $16,5,1$ species as observed upon addition of $\mathrm{Me}_{2} \mathrm{AlOMe}$ to MAO (Figure 6b). 16,5,1 then undergoes a rearrangement reaction where the OMe unit is incorporated in the MAO oligomer and a $\mathrm{Me}_{2} \mathrm{AlOAIMe}_{2}$ unit is lost, followed by addition of $\mathrm{Me}_{3} \mathrm{Al}$ to give $15,5,1$ which is one MeAIO unit lower in MW than its precursor. The released $\mathrm{Me}_{2} \mathrm{AlOAIMe}_{2}$ is incorporated into unoxidized precursors of 16,6, which upon rearrangement and replacement of $\mathrm{Me}_{3} \mathrm{Al}$ will give the higher 
molecular weight 17,7 anion observed. This reactivity would explain the initial conversion of 16,6 into $16,5,1$ which over time converts into $15,5,1$ and 17,7 plus higher mass analogues. We have previously deduced that $\mathrm{Me}_{2} \mathrm{AIOAIMe}_{2}$ is present in aged MAO solutions ${ }^{[14 \mathrm{~d}]}$ so it is likely present in unaged MAO solutions as well. Stoichiometrically, $\mathrm{Me}_{2} \mathrm{AIOAIMe}_{2}$ is equivalent to $\mathrm{MeAIO}+\mathrm{Me}_{3} \mathrm{Al}$, so its addition to an MAO oligomer results in both $\boldsymbol{x}$ and $\boldsymbol{y}$ increasing by 1 . Invoking the participation of $\mathrm{Me}_{2} \mathrm{AIOAIMe}$ also provides an explanation for why oxidation seems to speed the aging of the non-oxidized oligomers (Figure 1). Oxidation generates the $\mathrm{Me}_{2} \mathrm{AIOAIMe}_{2}$ fragment, which can then go on to react with other oligomers and increase their molecular weight.

\section{Conclusions}

MAO oxidizes through reaction of $\mathrm{O}_{2}$ with free $\mathrm{Me}_{3} \mathrm{Al}$ to form $\mathrm{Me}_{2} \mathrm{AlOMe}$, which is slowly incorporated into MAO oligomers. This is confirmed by direct addition of $\mathrm{Me}_{2} \mathrm{AIOMe}$ to MAO solutions. Incorporation of $\mathrm{Me}_{2} \mathrm{AlOMe}$ does not seem to proceed by addition alone: it also appears to make the product amenable to picking up another equivalent of $\mathrm{Me}_{3} \mathrm{Al}$, and that species generates $\mathrm{Me}_{2} \mathrm{AlOAIMe}$ and a lower molecular weight oxidized oligomer. The $\mathrm{Me}_{2} \mathrm{AlOAIMe}_{2}$ gets incorporated into other oligomers, effectively adding (MeAIO $+\mathrm{Me}_{3} \mathrm{Al}$ ) to those oligomers and increasing their molecular weight. Oxidized products do still lose $\left[\mathrm{Me}_{2} \mathrm{Al}\right]^{+}$ and age via the same pathway as "regular" MAO. Potential formation of AIOMe fragments should be taken into consideration in the study of the structure and properties of MAO. ESI-MS provides a simple and highly sensitive means of assessing the extent of oxidation of a given sample of MAO, via inspection of the sample in negative ion mode in the presence of OMTS. Oxidation produces a tell-tale signature via the appearance of peaks $16 \mathrm{Da}$ higher (= $42 \mathrm{Da}$ lower) than the unoxidized oligomeric MAO anions. In conjunction with previous insights into aging of MAO, a detailed compositional picture of the ways in which MAO evolves over time is emerging.

\section{Experimental Section}

$\mathrm{Me}_{2} \mathrm{AIOMe}$ was prepared according to literature procedures. ${ }^{[18]} \mathrm{MAO}$ (10 and $30 \mathrm{wt} \%$ in toluene) was obtained from Albemarle and stored in the glove box freezer upon receiving. The samples were warmed to room temperature and thoroughly swirled to dissolve any precipitated content prior to use. $\mathrm{Me}_{3} \mathrm{Al}$ and $\left[\mathrm{Me}_{2} \mathrm{Al}\right]^{+}$concentrations of the MAO samples were determined following literature procedures. ${ }^{[17]}$ OMTS (98\%) was purchased from Sigma-Aldrich and used as received. 
THF and toluene were dried using a MBraun SPS drying system and stored over activated molecular sieves. Fluorobenzene (Oakwood) was refluxed over $\mathrm{CaH}_{2}$, distilled under $\mathrm{N}_{2}$ and dried over molecular sieves inside a glove box for at least 3 days prior to use. $\mathrm{O}_{2}(99.5 \%)$ was purchased from Airgas and dried by passage through a column of MS $4 \AA$ for use in oxidation of MAO solutions.

\section{ESI-MS Details}

In a typical procedure, a stock solution $(3 \mathrm{~mL})$ was prepared from MAO $(0.5 \mathrm{~mL}$ of $1.5 \mathrm{M}(10 \%)$ or $0.15 \mathrm{~mL}$ of $4.6 \mathrm{M}(30 \%)$ and the amount of a PhF solution of OMTS (0.015 M) needed to give the desired OMTS:MAO ratio. In the case of oxidized or diluted mixtures, these ratios were adjusted to give as close to the same concentration as possible. After mixing, $0.2 \mathrm{~mL}$ of this solution was further diluted to a total volume of $3 \mathrm{~mL}([\mathrm{Al}]=0.017 \mathrm{M})$. This was injected from the glove box to a Micromass QTOF micro spectrometer via PTFE tubing (1/16" o.d., 0.005" i.d.). Capillary voltage was set at $2700 \mathrm{~V}$ with source and desolvation gas temperature at $85{ }^{\circ} \mathrm{C}$ and $185{ }^{\circ} \mathrm{C}$, respectively with the desolvation gas flow at $400 \mathrm{~L} / \mathrm{h}$. MS/MS data were obtained in product ion spectra using argon as the collision gas and a voltage range of 2-100 V.

\section{Oxidation of MAO}

Caution is advised when attempting to oxidize alkylaluminum reagents with $\mathrm{O}_{2}$ as the reaction is strongly exothermic.

Direct Oxidation $\mathrm{O}_{2}: 1 \mathrm{~mL}$ of a $30 \mathrm{wt} \% \mathrm{MAO}$ solution was diluted with $3 \mathrm{~mL}$ of toluene and placed in a $25 \mathrm{~mL}$ Schlenk flask. The flask was fitted with a septum and dried $\mathrm{O}_{2}$ was carefully bubbled through the solution resulting in immediate gelation. $\mathrm{O}_{2}$ exposure was stopped after 5 sec. and the obtained suspension was filtered and the soluble parts were analyzed by ESI-MS.

Direct Oxidation, Dried Air: $1 \mathrm{~mL}$ of a $30 \mathrm{wt} \%$ MAO solution was diluted with $3 \mathrm{~mL}$ of toluene and placed in a $25 \mathrm{~mL}$ Schlenk flask. The flask was fitted with a septum and evacuated and back filled dried air. Mild gelation was observed and the mixture was filtered prior to analysis.

Indirect Oxidation: $5 \mathrm{~mL}$ of toluene were sparged with dried $\mathrm{O}_{2}$ and used to dilute 30 wt\% samples of MAO. Blank experiments with regular non-diluted and dry toluene diluted MAO were carried out to monitor the difference in oxidation. These spectra are shown in Figure S4. 
$\mathrm{Me}_{2}$ AlOMe Addition: A solution of $\mathrm{Me}_{2} \mathrm{AlOMe}$ in toluene (2M) was prepared in situ, and $2.3 \mathrm{~mL}$ of this solution was added to $30 \mathrm{wt} \% \mathrm{MAO}$. The resulting mixture was kept for multiple days during which its anion spectrum was periodically analyzed.

\section{Author Information}

Corresponding author: mcindoe@uvic.ca

The authors declare no competing financial interest.

\section{Acknowledgements}

We thank NOVA Chemicals' Centre for Applied Research for financial support and useful discussions. We thank Albemarle Corp. for a kind donation of $30 \mathrm{wt} \% \mathrm{MAO}$, and Dr. Bill Beard for helpful discussions. J.S.M. thanks NSERC (Strategic Project Grant \# 478998-15) for operational funding and CFI, BCKDF, and the University of Victoria for infrastructural support. S. C. acknowledges support for a visiting scientist position from the University of Victoria.

\section{References}

[1] a) M. Bochmann, Organometallics 2010, 29, 4711-4740; b) E. Y. -X. Chen, T. J. Marks, Chem. Rev. 2000, 100, 1391-1434.

[2] a) H. S. Zijlstra, S. Harder, Eur. J. Inorg. Chem. 2015, 2015, 19-43; b) W. Kaminsky, Macromolecules 2012, 45, 3289-3297; c) J. N. Pédeutour, K. Radhakrishnan, H. Cramail, A. Deffieux, Macromol. Rapid. Commun. 2001, 22, 1095-1123.

[3] D. W. Imhoff, L. S. Simeral, S. A. Sangokoya, J. H. Peel, Organometallics 1998, 17, 1941-1945.

[4] V. Busico, A. Pastore, A. Macchioni, Dalton Trans. 2013, 42, 9104-911.

[5] See for example: M. Linnolahti, S. Collins, ChemPhysChem 2017, ASAP; b) M. S. Kuklin, J. T. Hirvi, M. Bochmann, M. Linnolahti, Organometallics 2015, 34, 3586-3597; c) M. Linnolahti, A. Laine, T. A. Pakkanen, Chem. Eur. J. 2013, 19, 7133-7142; d) E. Zurek, T. Ziegler, Progress in Polymer Science 2004, 29 107-148.

[6] D.B. Malpass in Handbook of Transition Metal Polymerization Catalysts, R. Hoff, R. T. Mathers, Eds. John Wiley \& Sons, Hoboken, NJ, 2010, pp 1-28.

[7] See e.g. G. W. Kabalka, R. J. Newton, Jr. J. Organomet. Chem. 1978, 156, 65-69 and references therein.

[8] See e.g. A. L. Mogstad, R. M. Waymouth, Macromolecules, 1992, 25, 2282-2284.

[9] a) T. Mohle, E. A. Jeffrey in Organoaluminum Compounds, Elsevier Publishing Company, Amsterdam-London-New York, 1972; b) J. J. Ligi, D. B. Malpass in Aluminum Alkyls, Encyclopedia of Chemical Processing and Design, Volume 3 pp. 1-56, Marcel Dekker, New York and Basel, 1977.

[10] Y. Alexandrov, N. N. Vyshinskii, V. N. Kokorev, V. A. Alferov, N. V. Chikinova, G. I. Makin, J. Organomet. Chem. 1987, 332, 259-269

[11] B. S. Ault, J. Organomet. Chem. 1999, 572, 169-175.

[12] L. S. Santos, J. O. Metzger, Angew. Chem., Int. Ed. 2006, 45, 977-981.

[13] J. Jiang, H. Zhang, M. Li, M. T. Dulay, A. J. Ingram, N. Li, H. You, R. N. Zare Anal. Chem. 2015, 87, 8057-8062.- 
[14] a) S. Collins, M. Linnolahti, M. G. Zamora, H. S. Zijlstra, M. T. R. Hernández, O. Perez-Camacho, Macromolecules 2017, 50, 8871-8884; b) H. S. Zijlstra, M. Linnolahti, S. Collins, J. S. Mclndoe, Organometallics 2017, 36, 1803-1809; c) T. K. Trefz, M. A. Henderson, M. Linnolahti, S. Collins, J. S. Mclndoe, Chem. Eur. J., 2015, 21, 2980-2991. d) M. A. Henderson, T. Trefz, S. Collins, J. S. Mclndoe, Organometallics 2013, 32, 2079-2083.

[15] The number of $\mathrm{Me}_{3} \mathrm{Al}$ losses in the MS-MS spectra are in excess of those in the formula, which conveys compositional rather than structural information. At high collision energies, a rearrangement reaction involving structurally incorporated $\mathrm{Me}_{2} \mathrm{Al}$ groups and adjacent AlMe groups to produce $\mathrm{Me}_{3} \mathrm{Al}$ appears reasonable see ref. 19 .

[16] W. Kaminsky, C. Strübel, J. Mol. Catal. A: Chem., 1998, 128, 191-200 and references therein.

[17] F. Ghiotto, C. Pateraki, J. Tanskanen, J. R. Severn, N. Luehmann, A. Kusmin, J. Stellbrink, M. Linnolahti, M. Bochmann, Organometallics 2013, 32, 3354-3362.

[18] M. M. Kireenko, E. A. Kuchuk, K. V. Zaitsev, V. A. Tafeenko, Y. F. Oprunenko, A. V. Churakov, E. K. Lermontova, G. S. Zaitseva, S. S Karlove, Dalton Trans. 2015, 44, 11963-11976.

[19] E.P. Talsi, N.V. Semikolenova, V.N. Panchenko, A.P. Sobolev, D.E. Babushkin, A.A. Shubin, V.A. Zakharov, J. Mol. Catal. A: Chem. 1999, 139, 131-137. 


\section{FULL PAPER}

Oxidation of methylalumoxane (MAO) oligomers is studied using mass spectrometry. Exposure of MAO to $\mathrm{O}_{2}$ shows formation of oligomers with OMe units formed through $\mathrm{Me}_{2} \mathrm{AlOMe}$ incorporation. This reactivity and the subsequent changes in MAO's structure provide new insights into the complex nature of this important activator.

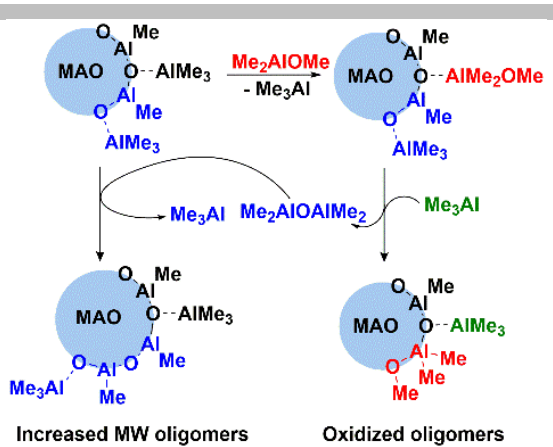

H. S. Zijlstra, S.Collins, J. S. Mclndoe*

Page No. - Page No.

Oxidation of Methylalumoxane Oligomers 